SHORT REPORT

\title{
Pulmonary tuberculosis and extreme prematurity
}

\author{
J Katumba-Lunyenya, V Joss, P Latham, C Abbatuan
}

Arch Dis Child Fetal Neonatal Ed 2005;90:F178-F183. doi: 10.1136/adc.2004.056549

\begin{abstract}
A mother, newly found to be positive for HIV, delivered her first baby at 25 weeks gestation. The infant initially did well in spite of a symptomatic patent duct and a severe intraventricular haemorrhage, but became severely unwell needing further respiratory support on day 18. Acid fast bacilli were found in endotracheal secretions. After the baby's death, the bacilli were confirmed to be Mycobacterium tuberculosis, and the same organism was grown from the mother's urine. The case raised challenging issues in relatively uncharted territory in terms of treatment of the infant, public health issues, ethical decision making, and media management.
\end{abstract}

$\mathrm{T}$ he mother was from sub-Saharan Africa and in a stable marriage with the child's father. On a routine HIV screen, she was found to be positive with very high viral load at 23 weeks gestation. Before further investigations could be completed, and before starting antiretoviral therapy, she developed a fever at $24^{+4}$ weeks, without a cough or other symptoms. She was started on antiretroviral therapy and antibiotics. All bacterial and viral tests failed to identify an infection. She failed to respond to various combinations of antibiotic treatment including pentamidine and cotrimoxazole. A chest physician found no evidence of tuberculosis. At $25^{+4}$ weeks gestation she went into labour. The father was not aware of the mother's HIV status and she was not yet ready to tell him.

After vaginal delivery, the baby, weighing $870 \mathrm{~g}$, was in good condition; she was intubated and given surfactant. Cranial ultrasound on the first day showed severe bilateral intraventricular haemorrhages with acute ventricular dilatation and a left haemorrhagic venous infarct. She was started on triple antiretroviral therapy (zidovudine, nevaripine, lamivudine) plus amoxycillin and gentamicin. We discussed the situation, other than the HIV status, with her parents; and we gently encouraged the mother to inform her husband about the HIV.

Although the baby managed nasal continuous positive airway pressure in air by 24 hours, she collapsed at day 6 and was reventilated because of a large patent arterial duct. She was therefore given indomethacin and soon successfully extubated back into air. At 18 days she was reventilated for major apnoeic episodes. Aspergillus fumigatus was isolated from a skin lesion and yeasts from the urine, so we gave ceftazidime, vancomycin, and liposomal amphotericin, but she worsened, with pyrexia and rising $C$ reactive protein concentrations. Copious tracheal secretions were negative on culture for bacteria, Aspergillus, and Pneumocystis carinii. We sent off more secretions to test for mycobacteria. Echocardiography did not show vegetations in the heart. She developed post-haemorrhagic hydrocephalus.

The baby's secretions were positive for acid fast bacilli on staining, so we started her on rifampicin, pyrazinamide, and isoniazid. She was by now very unwell, with no respiratory effort during endotracheal tube changes and few spontaneous movements. After discussion with the parents and relatives, intensive care was discontinued and she died soon afterwards. The mother had been started empirically on antituberculous therapy without laboratory confirmation of infection. Several days after her baby had died, her urine grew Mycobacterium tuberculosis.

\section{DISCUSSION}

As the number of mothers found to be positive for HIV is rising, and some of these women may already have tuberculosis, this type of case may arise again. Although there are other case reports of congenital tuberculosis in term and preterm babies, ${ }^{1-3}$ we present this case and the accompanying commentaries because it raises a set of important issues.

Congenital tuberculosis is very rare. Only about 300 cases had been reported in the English literature by $1984^{12}$ and only about another 77 thereafter to 2002. ${ }^{3}$ Placental $^{4}$ and endometrial $^{56}$ biopsy could facilitate early diagnosis in suspected cases before cultures became positive in the infant.

We would like to highlight four particular issues. Firstly, the advice and information from various experts was often conflicting or impractical, and it was clear that no one group of people knew enough to deal with all the issues. This emphasises the importance of a multidisciplinary meeting at an early stage.

Secondly, two different ventilators and a nasal continuous positive airway pressure driver had been used for this infant. These were put out of commission pending advice on decontamination.

Thirdly, there are very limited data on the optimal dosage of antituberculous and antiretroviral drugs in preterm infants.

The final issue is management of neonatal contacts. The high risk contacts, defined as infants nursed at any period of their stay in the same "hot room" as this case, and medium risk contacts, defined as infants nursed at any time of their stay in the cubicles opening on to the hot room, were given prophylactic isoniazid for three months followed by Heaf testing. The low risk contacts (infants nursed in the separate "cold room") were monitored by their general practitioners.

We have learnt that we need to consider tuberculosis as a possible infection for any infant with a mother infected by HIV. We now know how to decontaminate the ventilators should we find ourselves in a similar situation; we can supply details of this. We have started using a filter routinely on the expiratory limb of all our ventilators and continuous positive airways pressure drivers to prevent dissemination of infection to the atmosphere. We should avoid overzealous treatment of possible contacts. We have learnt that it is important to hold a multidisciplinary meeting at an early stage to agree the overall management of the case. It is important to actively manage information to the media, while respecting confidentiality, rather than risk a leaked story causing sensationalist reporting. We have learnt that, although it is important to counsel the mother and maintain 
confidentiality, it is also important to point out to her the responsibility and duty she owes to her relatives and the general population.

We were caught up in an unusual situation from which we have learnt much. Other units may feel that, in the light of worked out in advance to deal with this contingency. The commentaries that follow pick up on some of the issues that

\section{ACKNOWLEDGEMENTS}

We are grateful to Drs Kevin Ives and Raymond Brown for their helpful comments during the writing of this case report.

\section{Authors' affiliations \\ J Katumba-Lunyenya, V Joss, P Latham, C Abbatuan, Milton Keynes NHS Trust, Milton Keynes, UK \\ Competing interests: none declared}

Correspondence to: Dr Katumba, NICU, Milton Keynes NHS Trust, Eaglestone, Standing Way, Milton Keynes MK6 5LD, UK; jasper.katumba@mkgeneral.nhs.uk

Accepted 2 September 2004

\section{REFERENCES}

1 Snider DE, Bloch AB. Congenital tuberculosis. Tubercle 1984;65:81-2.

2 Lee LH, Le Vea CM, Graman PS. Congenital tuberculosis in a neonatal intensive care unit: case report, epidemiological investigation, and management of exposures. Clin Infect Dis 1998;27:474-7.

3 Laartz BW, Narvarte HJ, Holt D, et al. Congenital tuberculosis and management of exposures in a neonatal intensive care unit. Infect Control Hosp Epidemiol 2002;23:573-9.

4 Abughali N, Van der Kuyp F, Annable W, et al. Congenital tuberculosis. Pediatr Infect Dis J 1994;13:738-41.

5 Senbil N, Sahin F, Caglar MK, et al. Congenital tuberculosis of the ear and parotid gland. Pediatr Infect Dis J 1997;16:1090-1.

6 Popli MB, Mehta N, Nijhavan VS, et al. Congenital tuberculosis. Australas Radiol 1998:42:256-7. our experience, it would be useful to have a written plan we have raised.

the mother is known to have tuberculosis, transmission has been shown to be postnatal by nosocomial spread. However, there are no specific data on pregnancies complicated by both HIV and tuberculosis with regard to vertical transmission of tuberculosis, and in this situation the risk of in utero transmission may be different.

This case described by Katumba-Lunyenya et al highlights the need for a multidisciplinary approach to women with HIV in pregnancy, whether they are unwell or not. The multidisciplinary team should include:

- a consultant in adult infectious diseases or genitourinary medicine

- a consultant obstetrician

- a consultant in microbiology/virology

- a consultant in paediatric diseases

- a neonatal consultant

- an HIV support worker

It is particularly important to have a consultant microbiologist/virologist who can advise on the most appropriate specimens required and advise on sensitivities, etc.

The role of the HIV support worker/advisor is extremely important as they spend a great deal of time with these women, discussing all aspects of care and in particular confidentiality issues. Their role in being the patient advocate cannot be underestimated.

The obstetrician has an important role to play in explaining that a whole variety of carers will need to know the patient's HIV status in the best interests of both the mother and the baby. They need to encourage some documentation of the HIV status and plan for delivery in the hand held maternity notes. However, at all times the patient's wishes have to be respected, but the decision to withhold information must be informed, and consent sought for all relevant information to be held in a separate file and released on a "need to know" basis.

Many women with HIV deliver prematurely; the cause is not known. In this case the mother was clearly unwell, and whether the cause of the pyrexia was intrauterine had to be considered. Although the outcome is devastating for the parents, without an established diagnosis it would have been unwise to attempt to delay delivery by the use of tocolytic drugs.

P Hurley Women's Centre, John Raddliffe Hospital, Oxford, UK; pauline.hurley@orh.nhs.uk

which increased to 758 in $2002{ }^{1}$ This probably reflects an increase in incidence as well as an increase in "identification" by the introduction of routine antenatal screening. The success of routine antenatal screening is, however, variable, with the target of $90 \%$ of pregnancies being screened being achieved in very few areas. This highlights the need for far more training of both midwives and obstetricians, discussing openly the benefit and need for antenatal testing.

About three quarters of all women, globally, who are infected with HIV come from sub-Saharan Africa.

There has also been an increase in the incidence of tuberculosis, and this resurgence may, in some part, be due to the susceptibility of the HIV infected patient to this disease. Women from sub-Saharan Africa need to be screened thoroughly, and tuberculosis in particular should be considered when they have pyrexia of unknown origin and are known to be HIV positive. Significant pyrexia in pregnancy is known to trigger premature labour, and the cause needs to be identified urgently and effective treatment established as soon as possible.

In utero transmission of tuberculosis leading to congenital infection is rare. Even with vaginal delivery, in cases where
ROUTE OF INFECTION AND INFECTIVITY
Neonatal tuberculosis is usually caused by someone, usually the mother, with open pulmonary tuberculosis coughing on 
the baby. ${ }^{1}$ This mother apparently did not have open tuberculosis, so spread must have been transplacental, leading to disseminated, congenital tuberculosis. Did the baby have clinical or autopsy evidence of extrapulmonary tuberculosis?

Most children with tuberculosis disease are not contagious. Exceptions include children with adult-type cavitary lung disease, those with sputum that is smear positive for acid fast bacilli, and those with congenital tuberculosis. ${ }^{2}$ This baby falls into both the last two categories, and artificial ventilation is likely to have increased the dissemination of bacilli by aerosol, as happens when a patient with chickenpox is ventilated.

\section{HOW TO PREVENT EXPOSURE OF OTHER BABIES AND STAFF?}

It is simplistic to say that a high index of suspicion of the diagnosis of neonatal tuberculosis, with early empirical treatment and isolation of suspect cases, is ideal. Neonatal tuberculosis is notoriously difficult to diagnose, especially in preterm babies requiring intensive care. ${ }^{3}$ Symptoms mimic bacterial sepsis, and the diagnosis is often delayed. ${ }^{13}$ What is more, many neonatal units do not have the facility to isolate a ventilated neonate, necessitating transfer of infectious neonates. There is also the risk of catching tuberculosis from the mother in cases associated with open maternal tuberculosis.

\section{DEFINITION AND MANAGEMENT OF CONTACTS}

Contact tracing in this situation is essentially no different from other tuberculosis exposures, and should be carried out by the local health authorities. ${ }^{12}$ All newborns in the nursery at the same time are contacts, even if ventilated. Newborn contacts constitute a high risk group, for which prophylactic isoniazid is recommended. Tuberculin skin testing after three months dictates further management: if negative, stop the isoniazid; if positive, examine the baby, obtain a chest radiograph, and if no evidence of infection, continue isoniazid to nine months. ${ }^{2}$ BCG vaccine reduces the risk of tuberculosis in exposed infants, but protection is not absolute. ${ }^{12}$ Isoniazid resistant BCG is no longer available, so BCG cannot be given simultaneously with isoniazid. United Kingdom ${ }^{4}$ and Australian ${ }^{5}$ authorities view BCG vaccine as an important adjunct to isoniazid, to be given to tuberculin negative tuberculosis exposed babies, especially if continued exposure is likely. BCG vaccine should not be given to HIV positive patients. ${ }^{3-5}$

\section{ETHICS}

A final ethical point. I believe that the prognosis of a 25 week gestation baby places an obligation on neonatologists: intensive care should not usually be initiated, and certainly not continued, without parental informed consent. In this case, the father can scarcely be deemed to have given informed consent to neonatal care if he was unaware of his baby's risk of HIV infection.

D Isaacs Children's Hospital at Westmead, Westmead, NSW 2145, Australia and University of Sydney; davidi@chw.edu.au

\section{REFERENCES}

1 Starke JR, Smith MHD. Tuberculosis. In: Remington JS, Klein JO, eds. Infectious diseases of the fetus and newborn infant. 5th ed. Philadelphia: WB Saunders, 2001:1179-97.

2 Pickering LD, ed. Red book: 2003 report of the Committee on Infectious Diseases. 26th ed. Elk Grove Village, IL: American Academy of Pediatrics, 2003:642-60
3 Isaacs D, Moxon ER. Handbook of neonatal infections: a practical guide. London: WB Saunders, 1999:388-91.

4 Salisbury DM, Begg NT, eds. 1996 Immunisation against infectious disease. London: HMSO, 1996:219-41.

5 NHMRC. The Australian immunisation handbook. 8th ed. Canberra: Commonwealth of Australia, 2003:230-5, Also available on http:// www.immunise.health.gov.au/handbook.htm.
$T^{1}$ he clinical difficulties faced by Katumba-Lunyenya et al when presented with a sick preterm infant at risk of perinatal transmission of HIV, who later had proven congenital tuberculosis and possible aspergillosis, are enormously challenging, even before considering the infection control, public health, public relations, and media issues that this case highlights.

\section{PREVENTING TRANSMISSION OF HIV}

The high maternal viral load, vaginal delivery, and premature birth are all likely to have increased the risk of perinatal transmission of HIV in this case. We do not know the mother's CD4 count or the circumstances of her delayed antenatal HIV test result. However, it seems possible that her CD4 count was low, and antiretroviral therapy may have been indicated earlier than 24 weeks on maternal health grounds if this information had been available to her doctors. The most important factor in relation to HIV transmission is probably maternal viral load, and this may be reduced by log numbers even if the antiretroviral therapy is only on board for a matter of days. Initiation of maternal antiretroviral therapy earlier in the second trimester might have driven immune reconstitution in the mother and a reduced risk of antenatal transmission of HIV (and possibly tuberculosis). HIV transmission risk would have been further reduced by caesarean section (if acceptable on obstetric grounds) and administration of intravenous zidovudine to the mother during the labour and delivery. The perinatal maternal drug loads the infant with zidovudine before the peak of exposure to HIV during delivery. Prophylaxis of the infant against HIV after birth is difficult in the sick preterm infant because of the availability of only one parenteral antiretroviral agent (zidovudine). There are no definitive studies of preventive strategies in extreme prematurity or optimal drug combinations, and all cases should be discussed with a specialist in paediatric HIV with regard to best current practice. Intravenous zidovudine should be administered to the sick preterm infant as soon as possible after birth. Single agent prophylaxis for HIV transmission is used routinely in low risk cases, but triple prophylactic therapy should be considered for infants who are considered to be at high risk of transmission of the virus, as in this case. Where the neonatologist considers enteral drugs acceptable, oral nevirapine and lamivudine should be added to the intravenous therapy with zidovudine. Such combinations have been used successfully at 27-28 weeks gestation in the United Kingdom in recent years ( $\mathrm{G}$ Tudor-Williams and $\mathrm{H}$ Lyall, personal communication). The intravenous preparation of zidovudine may be replaced by oral zidovudine when the neonate is able to tolerate enteral feeds, and treatment continued for four to 
six weeks. Monitoring of full blood count for anaemia and neutropenia is advised, and postnatal follow up of the infant to detect infection with HIV should be undertaken as for the term infant.

\section{CONGENITAL TUBERCULOSIS}

The case history strongly suggests that the infant was principally infected with Mycobacterium tuberculosis by aspiration of contaminated maternal secretions such as amniotic fluid (as happens when a caseous placental lesion ruptures) rather than through the placenta. It seems unlikely that this infant's tuberculosis could have been managed differently once recognised, and the demise was so rapid that the antituberculous therapy probably made little difference. This infant needed to receive antituberculous therapy much earlier, perhaps immediately after birth in order to have had a chance against this rare and overwhelming infection. But there was no suspicion of congenital tuberculosis at that stage. It is not clear when the mother was started on blind antituberculous therapy, but this information may have been helpful in planning neonatal management. Infections that compromise placental integrity may increase the risk of transmission of HIV. Clearly co-infection with opportunistic infections (notably sexually transmitted infections, toxoplasma, tuberculosis, cytomegalovirus, etc) must always be considered when an infant is born to an HIV infected mother. When congenital tuberculosis is suspected, a full clinical evaluation including lumbar puncture is required (if practical) and four drug therapy (typically isoniazid, rifampicin, pyrazinamide, and an aminoglycoside) initiated immediately, with addition of steroids if tuberculosis meningitis is present. Alternative drug regimens may be necessary in an infant who cannot tolerate oral agents and should be discussed with a specialist in paediatric infectious disease. Susceptibility testing of the organism once isolated and knowledge of drug resistance in the region where the mother is likely to have acquired the infection should be sought to guide treatment.

\section{FUNGAL INFECTION}

It seems likely that this infant had aspergillosis, as the organism was isolated from a skin lesion. It is not clear whether there were specific environmental risk factors in the neonatal unit (building work) or neutropenia in the infant. It seems very reasonable that the infant should receive empiric antifungal therapy, even without this isolate, in view of the deteriorating clinical situation in the context of apparent late onset sepsis and appropriate antibiotic therapy.

\section{CONCLUSION}

The authors have described a tragic case which highlights the need for improvements in delivery of routine antenatal screening to high risk populations and challenges us all to actively consider opportunistic infections when faced with a sick preterm infant in the context of a severely immunosuppressed mother with HIV. Central to delivering optimal prophylaxis of HIV and management of rare congenital infections is good communication between the HIV physician, the obstetrician, the neonatal team, and a specialist in paediatric infectious diseases.

\section{ACKNOWLEDGEMENTS}

I am grateful to H Lyall and G Tudor-Williams for helpful discussions.

\footnotetext{
A J Pollard

Oxford Vaccine Group, Department of Paediatrics, University of Oxford, John Radcliffe Hospital, Oxford OX3 9DU, UK; andrew.pollard@paediatrics.ox.ac.uk

UK resources: www.bhiva.org, http://www.bhiva.org/chiva/index. $\mathrm{html}$
}

\section{COMMENTARY}

$T$ he case reported by Katumba-Lunyenya et al raises a number of ethical and legal issues, particularly in relation to consent and disclosure of information.

The primary duty of the paediatrician is to act in the child's best interests as established by the Children $\mathrm{Act}^{1}$ and subsequent case law. ${ }^{2}$ Although Article 8 of the Human Rights Act 1998, the right for "respect of family and private life", is relevant, the House of Lords has determined that there is nothing in the Human Rights Act that will alter the interests of the child being paramount. ${ }^{3}$ Article 8 is not an absolute right and may be breached if the person:

- acts in accordance with the law

- is pursuing a legitimate aim

- has sufficient and relevant reason

- acts proportionately

Clearly, the mother was giving informed consent for neonatal intensive care and for the team's management. We are told that the father was the husband and hence also had legal parental responsibility. Although it is always good clinical practice to involve both parents in obtaining consent, in law only the consent of one with parental responsibility is required to proceed, and in emergency no consent is required but the baby's best interest prevails. ${ }^{4}$

In relation to HIV infected mothers, the courts have acted to require testing and treatment of infants for possible HIV infection against parental opposition. ${ }^{5}$

In relation to child protection, a paediatrician does not owe a duty of care to parents. ${ }^{6}$ However, in this case, does the paediatrician owe a duty of care to the spouse of a mother with HIV infection? Professor Sir Ian Kennedy writes that the duty to warn, established in the leading Unites States case of Tarasoff ${ }^{7}$ and tested in the United Kingdom ${ }^{8}$ in the context of HIV infection, will be problematic. Generally, people are not responsible for the consequences of unlawful acts committed by others. However, the General Medical Guidance is helpful in that a doctor may disclose that a patient is HIV positive to the patient's known sexual partner only when there is a serious and identifiable risk to that person. The doctor should, however, first try to persuade the patient to disclose the information voluntarily. If the patient refuses, the doctor should warn the patient that confidentiality will be breached. ${ }^{10}$

Hence, as highlighted by other commentaries, the increasing prevalence of HIV positive mothers will mean that the problems encountered in this case are likely to be encountered increasingly in neonatal and obstetric care.

A C Elias-Jones University of Leicester, Leicester, UK; alun.elias-jones@uhl-tr.nhs.uk

\section{REFERENCES}

1 Children Act. London: HMSO, 1989.

2 Re F. Mental Patient: Sterilisation AC1 1990:2.

3 Dawson v Wearmouth 1FLR 1999:1167.

4 Re R. 7BMLR 1991; 147:158.

$5 \operatorname{Re} C$ (A minor) High Court. 3/4/1999.

6 JD v East Berkshire Community NHS Trust and Others. EWCA Civ 2003:1 151.

7 Tarasoff $\vee$ Regents of the University of California 529 P 2d 55 (Cal, 1974).

8 W v Egdell. AllER 1990;1:835-849.

9 General Medical Council. Confidentiality: protecting and providing information. London: GMC, 2000.

10 The Medical Defence Union. Confidentiality. London: MDU, 1997:8. 
promise that professionals will respect confidentiality as part of the clinician-patient relationship. Also implied is that professionals will share information among themselves for the purpose of providing the best health care for patients. In this case, it is clear that passing information to the neonatologists about maternal HIV status enables them to deliver the best possible care to the baby. But passing information to the father about the HIV status of the mother may have adverse and unpredictable consequences on their relationship and may lead to a breakdown in trust between the mother and professionals.

The traditional view on the duty to respect confidentiality does permit breaches to prevent serious harm to others. ${ }^{5}$ In this case the infant is certainly at risk of serious harm from transmission of infection, and so is the father, provided that he was not the source of the maternal infection. There are risks of harm in future pregnancies. However, in this view of confidentiality, the burden is on those who wish to breach it to show that there are sufficient grounds for doing so.

An alternative view, which is more in keeping with current concepts of family therapy and provision of health care by multiple teams, involves joint ownership of shared information by the family and the healthcare teams. ${ }^{6}$ In this model the mother can ask that information about her is not released to others, but only if she can show that the release of the information is likely to cause her harm. She may feel that disclosure will compromise her relationship with the father or that she might be blamed for the illness and death of her child. However, it would seem unjust that the father does not have the opportunity of counselling and testing whereas his wife and child do so. Giving information to the neonatal team enables them to give treatment intended to benefit the baby, but is unlikely to harm the mother. This approach underlines the essential fairness of disclosure in this unfortunate situation, but questions as to the level of harm that should prevent disclosure remain.

Neither model addresses the timing of disclosure. It may not be necessary to disclose the mother's HIV status to initiate intensive care, but would be so if the child were to have survived for long enough to need long term antiretroviral therapy. Stepwise disclosure, at a pace the family can tolerate, may be seen to be analogous to the dynamic nature of the consent process, and may serve their best interests.

\section{WITHDRAWAL OF TREATMENT}

The decision to withdraw life sustaining treatment from the baby can be justified because the burdens of treatment to the baby and the family outweighed the benefits of continuing it and could improve neither her life nor potential. Indeed, given the clinical facts, there may have been grounds for discussing withdrawal of treatment before it was actually done, but such discussions would have needed to include confidential information and may have deprived the baby of the fullest possible opportunity to benefit. It is important that the process of decision making is perceived to be fair and just and that it is carefully documented

\section{SCOPE OF PROFESSIONAL DUTIES}

The primary duty of care of neonatologists is to babies, but they also have duties to relieve the distress of parents who face the illness and subsequent death of their child. Whether this obligation is sufficient justification to breach confidentiality (over the role of HIV transmission) is more conjectural. The parents do need this information to understand their child's illness, but imparting it is likely to require skilled counselling by HIV teams, working in partnership with neonatologists.

Professionals on the neonatal intensive care unit also have duties to the other patients under their care in preventing 
transmission of infection and prophylaxis, which derive from principles of justice and welfare. Prophylaxis requires consent that is sufficiently informed but which does not breach confidentiality. This is a sensitive issue demanding tact and discretion

Although the prevalence of HIV and tuberculosis infection may rise, it is not clear what protocols and procedures might be introduced that would cover all the ethical ramifications here. Early collection of information and multiagency discussion may be helpful, as may formal ethical review or use of a policy resource such as that provided by the UK Clinical Ethics Network. ${ }^{7}$ Part of the function of an ethics commentary is to empathise with and support those who face moral dilemmas whose outcome may depend on precedent and circumstance as much as principle. Overall it may be the process whereby decisions are made, rather than the outcome, that is important to the participants, and this should follow ethical principles.
V Larcher

Royal London Hospital, Whitechapel, London EI 1BB, UK; victor.larcher@bartsandthelondon.nhs.uk

\section{REFERENCES}

1 Royal College of Paediatrics and Child Health. Withholding or withdrawing life sustaining treatment in children: a framework for practice. 2nd ed. London: RCPCH, 2004.

2 Doyal L. Medical ethics and moral indeterminacy. J Law Soc 1990:17:1-16

3 Kennedy I, Grubb A. Medical law: text and materials. London: Butterworths, 2000.

4 Snowdon C, Garcia J, Elbourne D. Making sense of randomisation: response of parents of critically ill babies to random allocation of treatment in a clinical trial. Soc Sci Med 1997:45:1337-55.

5 General Medical Council. Confidentiality: protecting and providing information. London: GMC, 2000.

6 Parker M, Lucassen A. Genetic information: a joint account? BMJ 2004;329:165-7.

7 www.ethics-network.org.uk. 